it also includes clinicians who are particularly interested in the subject. This is important when it is realized how slowly the disease may grow and by what a variety of methods it may be treated-surgery, radiotherapy, radioisotopes, and thyroid hormones. As long ago as 1949 O. Cope and his colleagues $^{7}$ in Boston tried to define those thyroid nodules which were to be feared. The result of their retrospective survey was to incriminate above all others the solitary nodule as opposed to the multinodular goitre, and the same rule appears true today. A review of 207 clinically solitary nodules at Hammersmith Hospital ${ }^{8}$ disclosed 26 carcinomas, an incidence of $12.6 \%$, which is considerably above the rate in Manchester but possibly reflects the various selective stages through which the patients have been referred.

Another factor of importance in this problem is the apparent increase in the incidence of differentiated and, in particular, papillary carcinoma in the last 30 years. Crile ${ }^{9}$ drew attention to this in a paper this year in which he reviewed 307 patients treated by himself. Of these, $95 \%$ survived for five or more years, and he attributes the excellent results which have been especially noticeable since 1954 to giving thyroid by mouth. The rationale for this therapy was put forward originally by Sir Thomas Dunhill ${ }^{10}$ in Britain. He described a group of children with widely metastasizing thyroid carcinoma in whom the disease was well controlled when they were given dried thyroid by mouth. Crile, who can always be relied on to be provocative, states that most of the papillary cancers seen in his clinic since 1937 appeared as a result of radiation given in childhood for benign disease. The mechanism by which carcinoma is induced in childhood by ionizing radiation is now well recognized, but at least in this country many patients with carcinoma give no such history. It may be that the dosage necessary is even smaller than was at first contemplated, and probably other factors must also be present, in particular stimulation by thyrotrophin, as occurs in iodine deficiency and certain parts of the menstrual cycle.

Can any conclusions be drawn at this stage from the facts which at first sight seem so conflicting? Probably all that it is wise to say would be that thyroid carcinoma occurs much more commonly in single nodules than in multinodular goitre and is particularly to be suspected in the very young, because so many simple nodules appear in the third and fourth decades. Should all such solitary nodules be removed? This is an excellent field for a prospective study, which might be justified on the grounds that the lesions are so slow growing. The only disturbing factor would be the findings of the Houston workers ${ }^{11}$ that the deadly undifferentiated thyroid carcinoma of older patients usually arises in a differentiated tumour. Many doctors still wish to see these solitary nodules removed, since the operation carries so little morbidity when performed by a surgeon who is used to dealing with the thyroid gland.

' Cole, W. H., Majarakis, J. D., and Slaughter, D. P., Fournal of Clinical Endocrinology, 1949, 9, 1007.

Sokal, J. E., New England fournal of Medicine, 1953, 249, 393.

3 Doll, R., in Thyroid Cancer, ed. C. E. Hedinger. London, Heinemann, 1969.

- Knowlson, G. T. G., British Fournal of Surgery, 1971, 58, 253.

Crile, G., jun., and Dempsey, W. S., fournal of the American Medical Association, 1949, 139, 1247.

- Thyroid Tumour Registry: Secretary, Department of Pathology, Royal

I Cope, O., Dobyns, B. M., Hamlin, E., jun., and Hopkirk, J., Fournal of Clinical Endocrinology, 1949, 9, 1012.

- Taylor, S., and Psarras, A., Praxis, 1967, 56, 370

- Crile, G., jun., Surgery, Gynaecology and Obstetrics, 1971, 132, 460

10 Dunhill, T. P., Transactions of the Medical Society of London, 1937, 60, 234.

1 Clark, R. L., Hill, C. S., jun., and White, E. C., in Thyroid Cancer, ed. C. E. Hedinger. London, Heinemann, 1969

\section{Bronchial Mucocoele}

The term bronchial mucocoele has been used to describe a grossly dilated, mucus-filled bronchus retaining its normal connexions with the peripheral bronchi. The first two cases were described by B. H. Ramsey and F. X. Byron ${ }^{1}$ in 1953. Since then 17 further cases have been described. Recently

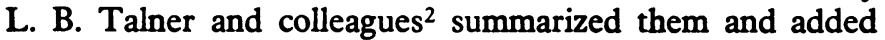
two more. They discuss the radiographic and anatomical characteristics and suggest the probable modes of development. In the same journal P. Lemire and colleagues ${ }^{3}$ discussed the radiology of six other cases.

Of the 27 cases reported and reviewed in these two articles bronchial mucocoele was found as a result of a routine chest radiograph in asymptomatic patients in 20, and 17 of the 27 cases were detected in patients under the age of 25 years. The typical radiological appearance is of a welldefined homogeneous, ovoid, and airless shadow occurring usually in the upper lobes and often demarcated from the hilum. The lesion is not always easily seen on the plain chest radiograph, but on tomography it appears as a sharply defined ovoid structure of increased density with a characteristic branching pattern. Bronchography will show that the bronchus leading to the mass is obstructed. Of diagnostic importance is the regional hyperinflation seen distal to the mucocoele. In most of the reported cases hyperinflation was readily visible radiographically and was confirmed at operation. The explanation for hyperinflation is discussed in these reports. Whereas obstruction to a lobar bronchus causes collapse of the lung distal to it, the lung distal to a segmental obstruction may remain aerated owing to collateral drift of air, and if the air drifts more readily on inspiration than on expiration regional hyperinflation might result.

On pathological examination the bronchus appears grossly dilated but the epithelial lining may be retained. The "cyst" is filled with viscid mucus, sometimes forming a cast with finger-like projections extending into the distal normal bronchi. The anatomy of the bronchial obstruction has been studied in detail. In some cases there appears to be complete bronchial atresia. In a few a membranous obstruction has been identified separating the mucocoele from the proximal bronchial tree. These membranes are easily missed unless the cyst is cut across in the longitudinal plane of the bronchus. Variable degrees of chronic inflammation are often found in association with a mucocoele, and this feature makes it difficult to decide in individual cases whether the bronchial obstruction arises as a congenital anomaly or as a post-infective stenosis. Atresia of a segmental bronchus has been described as an anomaly of bronchopulmonary development, 4 and this evidence together with the pathological features described, and the common occurrence of mucocoele in young asymptomatic people without a previous history of chest illness, suggests that the majority of cases so far reported are congenital in origin. T. S. Curry and G. C. Curry $^{5}$ have suggested that segmental atresia occurs most probably later than the fifteenth week of gestation, after development of the segmental bronchi, thus accounting for the normal peripheral bronchial anatomy.

Bronchial mucocoele has to be distinguished from other congenital abnormalities such as bronchogenic cysts, which do not have normal distal communications with the lung segment. Of the acquired lesions, mucus impaction of the bronchus 6 must be differentiated. Mucus impaction occurs mainly but not exclusively in asthmatic patients, and precipitins to Aspergillus fumigatus are found in a high pro- 
portion of cases seen in Great Britain. The bronchial obstruction in these cases is attributed to the plugs of inspissated mucus infiltrated with fungus mycelium, and bronchograms done after these plugs have cleared show varying degrees of proximal bronchiectasis but no evidence of segmental bronchial obstruction.

Most cases of bronchial mucocoele appear to have been submitted to surgery either because the diagnosis was in doubt, or because the mass was increasing in size, or because on theoretical grounds subsequent infection was feared. The fact that so many of these cases are diagnosed in asymptomatic adults suggests that bronchial mucocoele does not necessarily become readily infected. Now that the radiographic features have been so clearly described, diagnosis should not usually present a great problem. More conservative management might be considered, especially in those cases where regional overinflation is not severe and the mucocoele is not increasing in size.

1 Ramsay, B. H., and Byron, F. X., fournal of Thoracic Surgery, 1953,

2 Talner, L. B., Gmelich, J. T., Liebow, A. A., and Greenspan, R. H., American fournal of Roentgenology, Radium Therapy, and Nuclear Medicine, 1970, 110, 675.

- Lemire, P., Trepanier, A., and Herbert, G., American fournal of Roentgenology, Radium Therapy, and Nuclear Medicine, 1970, 110, 687.

- Simon, G., and Reid, L., British fournal of Diseases of the Chest, 1963, 57, 126.

- Curry, T. S., and Curry, G. C., American fournal of Roentgenology, Radium Therapy, and Nuclear Medicine, 1966, 98, 350

- Shaw, R. R., Fournal of Thoracic Surgery, 1951, 22, 149.

\section{Verdict on CS}

Critics of the use of CS as a riot-control agent in Northern Ireland might ponder on the 42 deaths that occurred ${ }^{1}$ when police and troops stormed Attica prison in the U.S.A.- the same week as the publication of the second report ${ }^{2}$ of the Himsworth Committe, set up to examine the medical aspects of CS. The committee decided to study the agent from a point of view "more akin to that from which we regard the effects of a new drug than to that from which we might regard a weapon." Nevertheless it seems clear that the use of CS has been effective in dispersing hostile crowds with an absence of morbidity and mortality that would have been impossible with more conventional methods.

Since its use in Londonderry in 1969 CS has been described as "more poisonous than chlorine and capable of being metabolized to cyanide" 3 and indeed the cyano groups in CS have been said to be the most likely source of systemic toxicity. ${ }^{4}$ The report makes it clear that this emotive link with cyanide has no justification. Even if all inhaled CS were retained and all converted to cyanide, the total amount derived from exposure for one minute to $10 \mathrm{mg} / \mathrm{m}^{3}$ of $\mathrm{CS}$ a level which is normally intolerable-is less than that derived from two puffs of a cigarette.

In general the report confirms earlier impressions ${ }^{5}$ that CS is remarkably non-toxic. The dosage that kills animals seems at least several hundred times greater than that which produces intolerable symptoms in man. The committee found no evidence that CS causes liver or kidney damage in man or that it has any teratogenic or abortifacient action. CS can, however, apparently cause blistering of the skin, and can cause acute exacerbations of chronic bronchitis. Neither the very young nor the very old seem unusually susceptible.

The committee considered that a person confined to a small, unventilated room with no means of escape might be exposed to dangerous levels of CS if a standard $12.5 \mathrm{~g}$ canister disseminated its full dose. The report recommends that care should be taken that CS missiles do not enter rooms and that a smaller missile should be developed for the rare occasion when eviction of a violent person justifies its use.

No one disputes that exposure to CS is an unpleasant experience. Indeed the reluctance of persons with experience of CS to risk re-exposure is one of the "advantages" claimed for CS over earlier tear gases. ${ }^{6}$ In fact some members of the committee themselves tried the effects of CS at a concentration of $35 \mathrm{mg} / \mathrm{m}^{3}$, far in excess of the level usually found tolerable, so some personal knowledge underlies their study of the matter. The most important of the committee's conclusions is that it highly improbable that circumstances could occur in civil operations in which exposure to CS might cause serious injury or death.

1 The Times, 15 September 1971.

Report of the Inquiry into the Medical and Toxicological aspects of CS (Orthochlorobenzylidene Malonitrile) Part II. Inquiry into Toxicological Aspects of $C S$ and its use for Civil Purposes. London, H.M.S.O., 1971. $50 \mathrm{p}$.

3 Jones, G. R. N., New Scientist and Science fournal, 17 June 1971.

Lancet, 1971, 1, 29.

5 British Medical fournal, 1969, 3, 546.

6 Penn, M. E., Ordnance, 1965, 50, 192.

\section{Accidents at Work}

For the first time in several years the number of fatal accidents in industry in Great Britain fell in 1970.1 In fact the 556 fatalities were the lowest annual total this century. The rate in relation to persons employed has been falling over the years for many : reasons, not the least of them being the vigilance of the Factory Inspectorate and, more important, the educative influence it has had on employers. Legislation too has enforced the fitting of safety devices in factories, scientific study has shown how some dangers can be eliminated, and some notoriously hazardous occupations such as coal mining now employ fewer men than they used to do. The result is a gratifying decrease from 17.5 deaths per 100,000 persons employed in 1901-10 to 11.6 in $1929-38$ to 4.5 in 1961-70. These figures are restricted to factories as distinct from all premises regulated by the Factories Act because the population at risk is not clearly identifiable outside them.

The number of non-fatal accidents notified to the Factory Inspectorate also fell in 1970 below the previous year's figure, being 304,595, and only just above the total for 1967. Regrettably, the Chief Inspector, Mr. B. H. Harvey, has to record that many accidents which are legally notifiable to the inspectorate are not in fact notified. The extent to which this failure to fulfil a legal obligation varies over the years is unknown, and this is one of several reasons why comparisons between different years cannot give much useful information about non-fatal accidents. What can be said unequivocally is that there are still far too many. Though cases do occur in which the real hazard of an industrial process fails to become apparent until years later, these are a small minority. Again the pace of technical advance in some industries is such that the people planning to introduce a new industrial process find themselves up against unexpected problems. As the report puts it: "We 